\title{
Bending response of a damaged ship hull girder predicted by the cyclic progressive collapse method
}

\author{
S. Li, Z. Hu \& S.D. Benson \\ Marine, Offshore and Subsea Technology Group, School of Engineering, Newcastle University, UK
}

This is a peer-reviewed, accepted author manuscript of the following paper: Li, S., Hu, Z. Q., \& Benson, S. D. (2019). Bending response of a damaged ship hull girder predicted by the cyclic progressive collapse method. In C. G. Soares (Ed.), Developments in the Collision and Grounding of Ships and Offshore Structures: Proceedings of the 8th International Conference on Collision and Grounding of Ships and Offshore Structures, ICCGS 2019 (pp. 111-119). (Marine Technology and Ocean Engineering Series; Vol. 4). CRC Press/Balkema.

\begin{abstract}
This paper applies the cyclic progressive collapse method to predict the bending response of a damaged ship hull girder. As an essential index of the structural performance, the residual load-carrying capacity of a damaged ship hull girder is particularly important for assessing the consequence of an accidental event. In this regard, considerable effort has been devoted to develop an efficient calculation methodology that can provide a reliable estimation of the residual ultimate bending strength of a damaged hull girder. However, the actual hull girder collapse can involve multiple load cycles, such as that experienced in a rough sea. The cyclic loading may lead to the onset of plasticity and local buckling, which can permanently reduce the overall strength of the ship hull. Hence a cyclic progressive collapse method is proposed. It follows the major assumptions and procedure embedded in the original Smith method with an extended capability to re-formulate the load-shortening curve of structural elements when an unloading or reloading is activated. A case study is carried out to predict the cyclic bending response of an asymmetrically damaged box girder model with various extents. The effect of the instantaneous neutral axis rotation is accounted for. Additionally, equivalent nonlinear finite element analysis is performed as a validation.
\end{abstract}

\section{INTRODUCTION}

Ships may experience various accidents during its service period, such as collision, grounding, severe hydrodynamic impact, fire and explosion. These accidental events can lead to structural damages in the form of denting, cutout and residual stress, which undoubtedly results in a loss of the structural performance compared with its intact status. In relation to the damage tolerance of a ship hull girder, the residual ultimate bending strength is a particularly critical criterion, which assists in a rapid decision-making relevant to the post-accident evacuation as well as maintenance.

In this respect, an efficient assessment methodology is desired. As a well-known and established approach, the simplified progressive collapse method (Smith method) has been widely applied in the evaluation of the residual strength of a damaged ship hull girder. The numerical benchmark study suggested that the simplified progressive collapse method is fairly well validated for the calculation of residual strength of a damaged ship (Guedes Soares et al., 2008). However, the actual collapse of a hull girder can involve multiple loading cycles, such as that encountered in a series of storm waves. Therefore, it might be crucial to predict the cyclic bending response of a ship hull girder. In this connection, Li et al. (2019a) proposed a cyclic progressive collapse method and the feasibility of the proposed method has been validated through a case study on intact cross sections.

In this paper, the cyclic progressive collapse method is applied to predict the bending response of an asymmetrically damaged ship hull girder. The influence of instantaneous neutral axis rotation is considered. Various damage extents and locations are analysed. In addition, nonlinear finite element analysis is conducted as a validation.

\section{BACKGROUND}

\subsection{Ship hull girder under cyclic bending}

It was indicated by the $14^{\text {th }}(2000)$ and $15^{\text {th }}(2003)$ ISSC ultimate strength committees that the structural capacity under cyclic loading can be significantly lower than the instantaneous collapse strength under a single load excursion. The reversal and accumulation of plastic deformation as well as local buckling can permanently degrade the structural resistance against subsequent loading, which eventually lead to an irreversible collapse.

Whist it is controversial, the cause of MOL Comfort wrecking might be relevant in this context. It was suggested that its failure was likely a dynamic cyclic process $\left(20^{\text {th }}\right.$ ISSC, 2018). 
Hess et al. (1997) reported the accident of an inland waterway oil bunker barge. It was revealed that the progressive damage caused by cyclic loading, which resulted in an inelastic behaviour, led to the final collapse of the barge.

A few experimental programmes were performed to investigate the collapse behaviour of a box girder under cyclic bending. Masaoka et al. (2006) performed a cyclic four-point bending test on a stiffened plated box girder structure. After several load cycles, the load-carrying capacity of the box girder dropped rapidly and a crack was initiated at the location where the plastic deformation concentrated. Four-point bending tests were also carried out by Cui and Yang (2018) on several box girders. It was reported that the box girder failed by an incremental collapse where the permanent deformation accumulated at each cycle. The initiation of crack, which was classified as the low-cycle fatigue crack due to large magnitude reversed straining, was also reported as one of the failure characteristics.

In terms of the structural response under cyclic loading, it is worth mentioning the shakedown limit state. This consideration was originally proposed by Jones (1975), in which a set of inequalities was introduced to calculate the shakedown limit of a ship hull under alternating sagging and hogging. A re-evaluation of the ship hull girder shakedown limit state was recently performed by Li and Benson (2019b) where the influence of buckling was accounted for. It was suggested that the safety margin based on a shakedown limit state may be significantly lower than that based on the orthodox ultimate limit state.

\subsection{Simplified progressive collapse method}

A comprehensive description of the simplified progressive collapse method can be found in Smith (1977) and Dow et al. (1981).

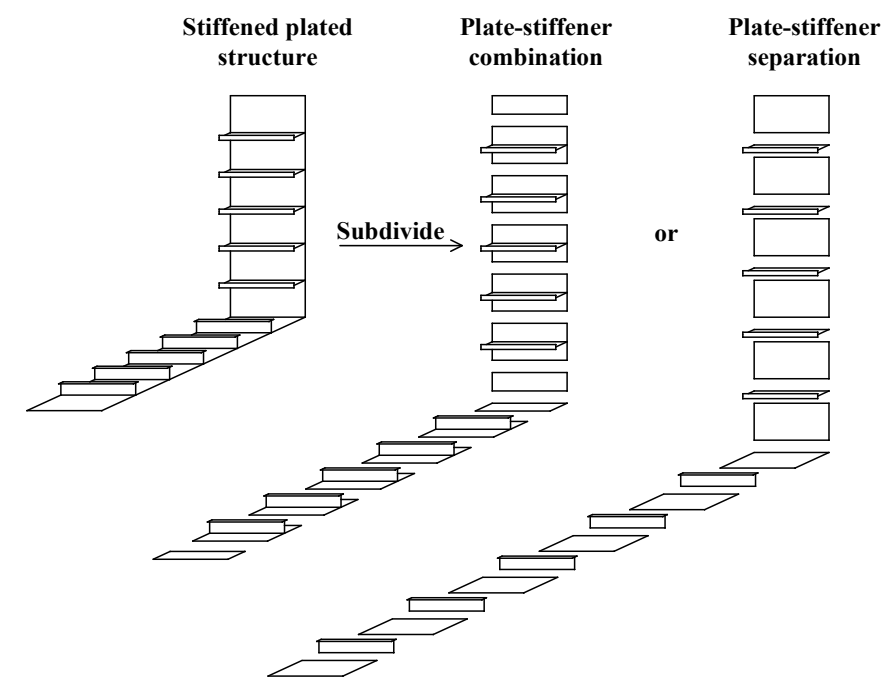

Figure 1. Subdivision of the cross section
In general, the bending moment/curvature relationship is predicted through an efficient procedure. The cross section is subdivided into structural elements (Figure 1) assuming that the interaction between elements does not exist. A load-shortening curve (LSC) characterising the response under inplane load is assigned to each element (Figure 2). It is assumed that all elements fail in an interframe mode. The curvature is applied incrementally with corresponding incremental strain being calculated on the assumption that cross section remains plane about the instantaneous neutral axis. Elemental tangent stiffness is derived from the load-shortening curve (LSC), by which the bending stiffness of the cross section can be evaluated. The position of the instantaneous neutral axis is recalculated and the bending moment increment is obtained by the multiplication of the bending stiffness curvature increment.

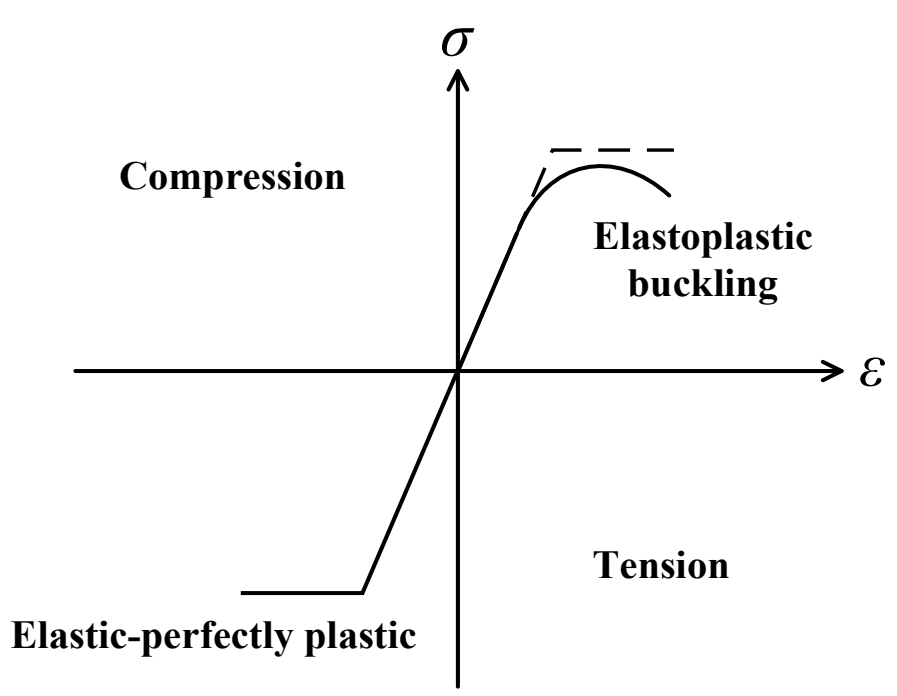

Figure 2. Schematic illustration of the load-shortening curve of structural element under in-plane load

\section{METHODOLOGY}

\subsection{Cyclic progressive collapse method}

The cyclic progressive collapse method proposed by Li et al. (2019a) follows the same framework described above. A summary of the methodology is provided in the following and a flowchart outlining the overall algorithm is given in Figure 3.

The method has an extended capability to re-formulate the LSC of structural element when an unloading or reloading is started. The re-formulation of LSC is driven by a loading protocol which allows the direction of each curvature increment to be controlled. When the direction of curvature increment is reversed, the re-formulation of LSC of each element will be activated. This updated LSC will be utilised for the subsequent Smith method calculation with standard procedure until the next curvature increment reversal. 


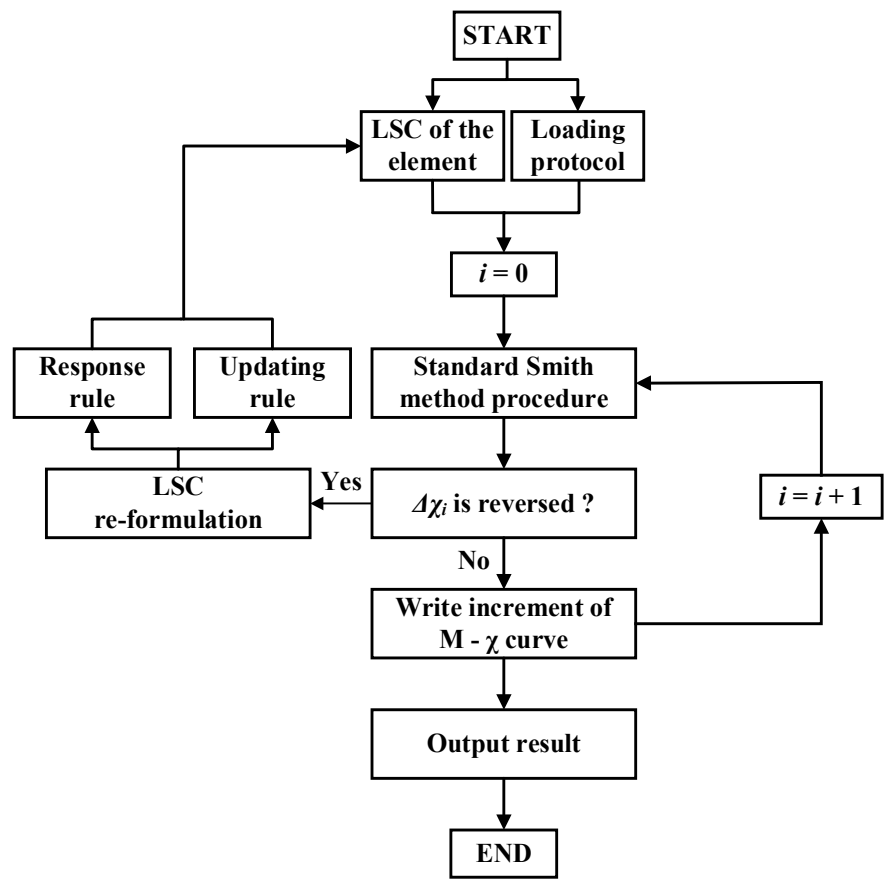

Figure 3. Principle algorithm of the cyclic progressive collapse method (Li et al., 2019b)

The re-formulation of the element LSC follows the analytical method introduced by Li et al. (2019c). The analytical method is derived based on the results of finite element analysis on a parametric series of unstiffened plates. The method is also proved being applicable for stiffened panels. It is formed of a response rule and updating rule. Given a strain increment, which can be the resultant of cross section curvature, the response rule will be called for predicting the stress increment. When the re-formulation is required, the updating rule will be activated to update the relevant data processed in the response rule. The same set of data will be utilised in the following prediction until the next re-formulation. The analytical method requires an input of the monotonic LSC, which can be estimated by any established method, such as FEM and IACS method etc. For the present study, Paik's empirical formula (Paik and Thayamballi, 1997) is adopted to predict the compressive ultimate strength of stiffened panel, while the ultimate strain value is taken as the material yield strain. The compressive LSC is assumed as piece-wise linear where the post-ultimate stiffness is taken as $-25 \%$ of the initial compressive stiffness. On the other hand, the monotonic tensile LSC follows the elastic-perfectly plastic material stress-strain curve.

\subsection{The rotation of instantaneous neutral axis}

For an asymmetrically damaged cross section, the analysis should be taken as a biaxial bending problem, which is in contrast to the case of an intact cross section where the vertical bending moment induces vertical bending exclusively. This is due to the fact that the neutral axis will be rotated during the progressive collapse. The rotational angle $\theta$ can be estimated by Equation (1). $\theta=\frac{1}{2} \tan ^{-1} \frac{D_{H V}+D_{V H}}{D_{H H}-D_{V V}}$

Fujikubo et al. (2012) derived the incremental bending moment-curvature equation for an asymmetrically damaged cross section under vertical bending. Two different cases are introduced, namely the pure vertical bending (Equation 2) and the constrained vertical bending (Equation 8). The former case accounts for the influence of neutral axis rotation, whereas no rotation of the neutral axis takes place in the latter case.

Pure vertical bending:

$\left\{\begin{array}{c}0 \\ \Delta M_{V}\end{array}\right\}=\left[\begin{array}{ll}D_{H H} & D_{H V} \\ D_{V H} & D_{V V}\end{array}\right]\left\{\begin{array}{l}\Delta \chi_{H} \\ \Delta \chi_{V}^{o}\end{array}\right\}$

where

$$
\begin{aligned}
& \Delta \chi_{H}=-\frac{D_{H V}}{D_{H H}} \Delta \chi_{V}^{o} \\
& \Delta M_{V}=\left(D_{V V}-\frac{D_{V H} D_{H V}}{D_{H H}}\right) \Delta \chi_{V}^{o} \\
& D_{H H}=\sum_{i=1}^{n} D_{i} A_{i}\left(y_{i}-y_{G}\right)^{2} \\
& D_{H V}=D_{V H}=\sum_{i=1}^{n} D_{i} A_{i}\left(y_{i}-y_{G}\right)\left(z_{i}-z_{G}\right) \\
& D_{V V}=\sum_{i=1}^{n} D_{i} A_{i}\left(z_{i}-z_{G}\right)^{2}
\end{aligned}
$$

Constrained vertical bending:

$$
\left\{\begin{array}{l}
\Delta M_{H} \\
\Delta M_{V}
\end{array}\right\}=\left[\begin{array}{ll}
D_{H H} & D_{H V} \\
D_{V H} & D_{V V}
\end{array}\right]\left\{\begin{array}{c}
0 \\
\Delta \chi_{V}^{o}
\end{array}\right\}
$$

where

$$
\begin{aligned}
& \Delta M_{H}=D_{H V} \Delta \chi_{V}^{o} \\
& \Delta M_{V}=D_{V V} \Delta \chi_{V}^{o}
\end{aligned}
$$

\section{CASE STUDY}

The case study is performed on a small scale model with various damage extents. First of all, a finite element validation is carried out. Next, a parametric study investigating the strength reduction during the cyclic loading is presented.

\subsection{Principal of the case study model}

Figure 4 shows the cross section of the case study model, which is intended to represent a double hull design. It has a width of $12000 \mathrm{~mm}$, a height of $8000 \mathrm{~mm}$ and is transversely framed every $1500 \mathrm{~mm}$. 
The thicknesses of the outer and the inner plating are $12 \mathrm{~mm}$ and $10 \mathrm{~mm}$ respectively. The material yield stress is $315 \mathrm{MPa}$ and Young's modulus is $207000 \mathrm{MPa}$ throughout the whole cross section. An elastic-perfectly plastic behaviour is assumed. The geometry and material configuration leads to five different combinations of plate slenderness ratio and column slenderness ratio (Table 1). Hard corners are introduced as the nearest plate element with respect to each intersection.

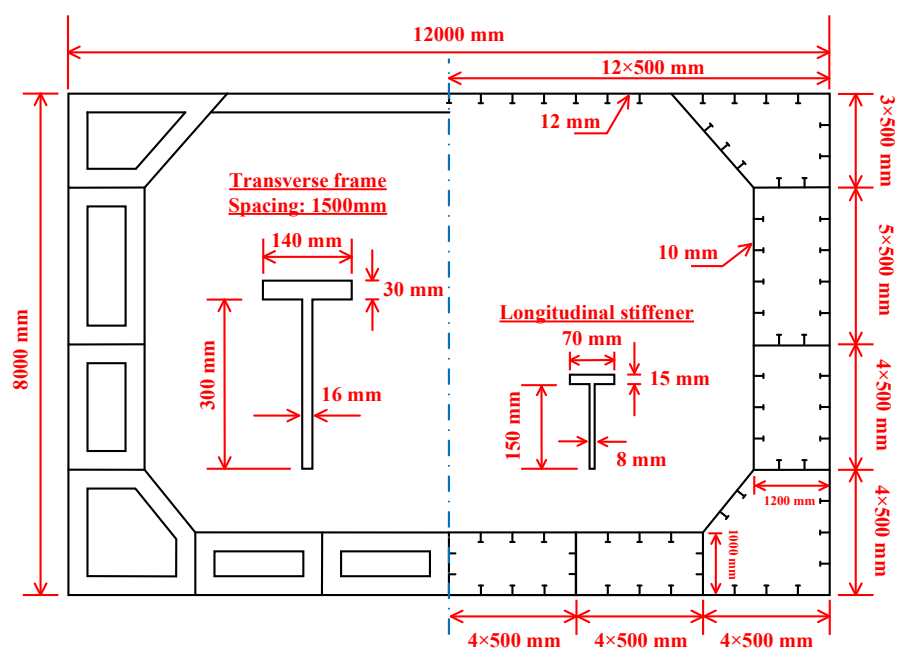

Figure 4. Double hull box girder cross section

Table 1. Plate slenderness and column slenderness ratios of the stiffened panel elements

\begin{tabular}{ccc}
\hline ID & $\beta$ & $\lambda$ \\
\hline D1 & 1.63 & 0.31 \\
D2 & 1.95 & 0.30 \\
D3 & 1.55 & 0.29 \\
D4 & 1.67 & 0.29 \\
D5 & 1.56 & 0.29 \\
\hline
\end{tabular}

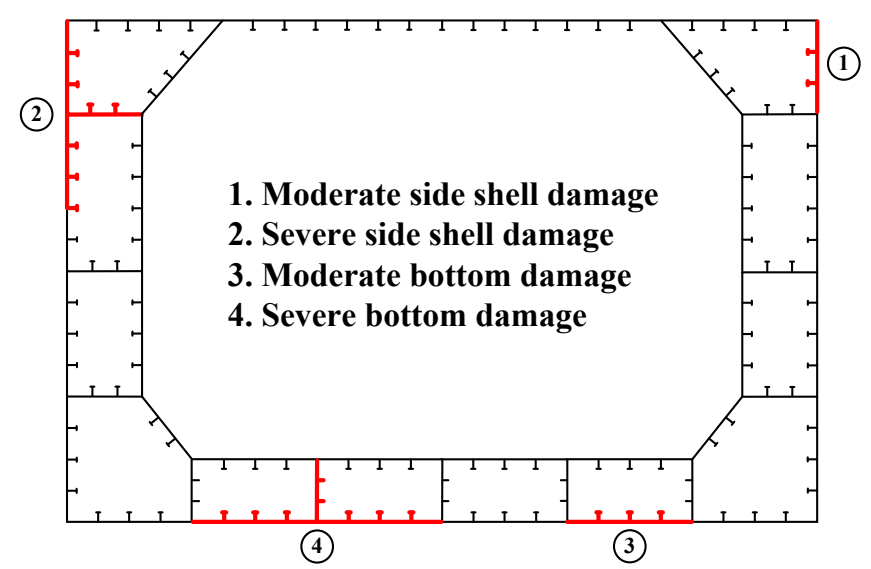

Figure 5. Four different damage scenarios

\subsection{Damage scenario}

In this paper, various damages are represented by removing the ineffective stiffened panels from the intact cross section. As shown in Figure 5, four different damage scenarios are investigated, namely
1. Moderate side shell damage;

2. Severe side shell damage;

3. Moderate bottom damage;

4. Severe bottom damage.

\subsection{Finite element validation}

A $1 / 2+1+1 / 2$ bay finite element model is utilised for validation. Due to the asymmetric damage, a fullwidth cross section is modelled with a characteristic mesh size of $100 \mathrm{~mm} \times 100 \mathrm{~mm}$. Initial deflection including local plate deflection $w_{p}$, column-type deflection $w_{c}$ and stiffener sideway deflection $v_{s}$ is applied on the model using a direct node translation technique. The deflection shape and amplitude are given by Equation (10) to (12). An illustration of these initial deflections is given in Figure 6. No welding-induced residual stress is considered.

$$
\begin{aligned}
\frac{w_{p}}{w_{o p}}= & \left\{0.8 \sin \left(\frac{\pi x}{a}\right)+0.2 \sin \left(\frac{m \pi x}{a}\right)\right. \\
& \left.+0.01 \sin \left[\frac{(m+1) \pi x}{a}\right]\right\} \sin \left(\frac{\pi y}{b}\right)
\end{aligned}
$$

$$
m=\operatorname{int}\left(\frac{a}{b}\right)+1
$$$$
w_{o p}=\min \left(6,0.1 \beta^{2} t\right)
$$$$
\frac{v_{S}}{v_{o s}}=\frac{z}{h_{w}}\left(0.8 \sin \left(\frac{\pi x}{a}\right)+0.2 \sin \left(\frac{i \pi x}{a}\right)\right)
$$

$i=\operatorname{int}\left(\frac{a}{h_{w}}\right)+1$

$$
\begin{aligned}
& \frac{w_{c}}{w_{o c}}=\sin \left(\frac{\pi x}{a}\right) \sin \left(\frac{\pi y}{B}\right) \\
& w_{o c}= \begin{cases}0.0008 a, & \lambda<0.2 \\
0.0012 a, & 0.2<\lambda<0.6 \\
0.0015 a, & \lambda \geq 0.6\end{cases}
\end{aligned}
$$

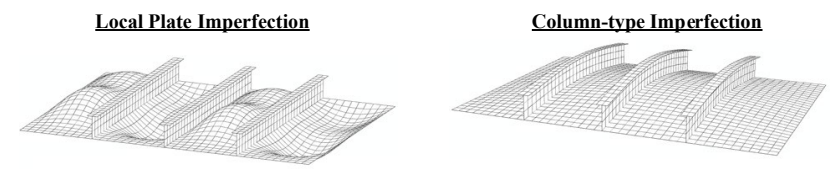

Stiffener Sideway Imperfection

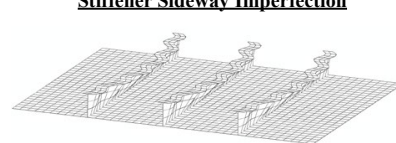

Figure 6. Illustration of the initial geometric imperfection 
The finite element analysis is conducted using the dynamic explicit solver. The incremental curvature is applied on a reference point tied to one end of the model, while the opposite end is fixed in six degrees of freedom. The validation is carried out to predict both monotonic and single-cycle responses of the intact and moderate side shell damaged models.

The bending moment/curvature relationships are shown in Figure 7 and 8 and a von-Mises stress distribution at the sagging ultimate collapse state is given in Figure 9. In general, the results show a close agreement in terms of the initial loading, unloading and reloading paths. A reasonable correlation of the ultimate bending moment is obtained. However, the initial bending stiffness predicted by the simplified method is lower than that predicted by NLFEM. This is attributed to the use of bilinear LSC which has a lower in-plane stiffness.

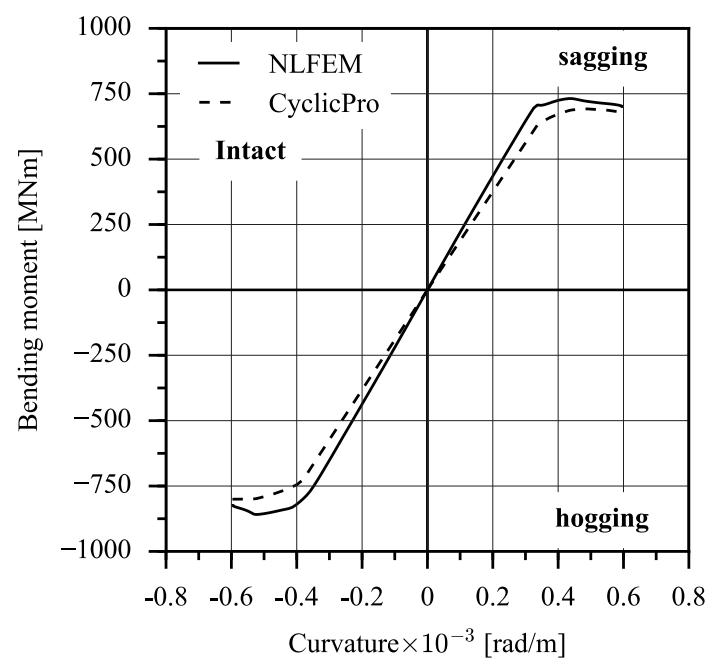

(a) Intact model

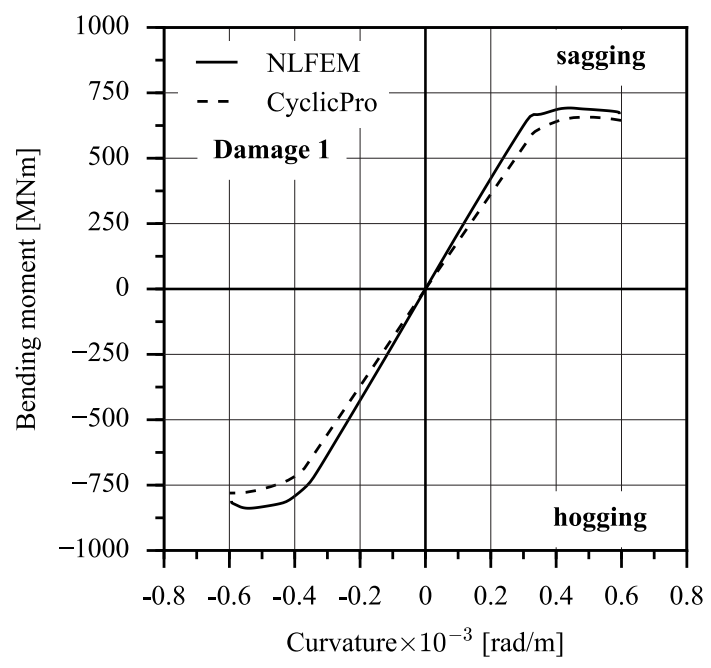

(b) Moderate side shell damaged model

Figure 7. Finite element validation (Monotonic analysis)

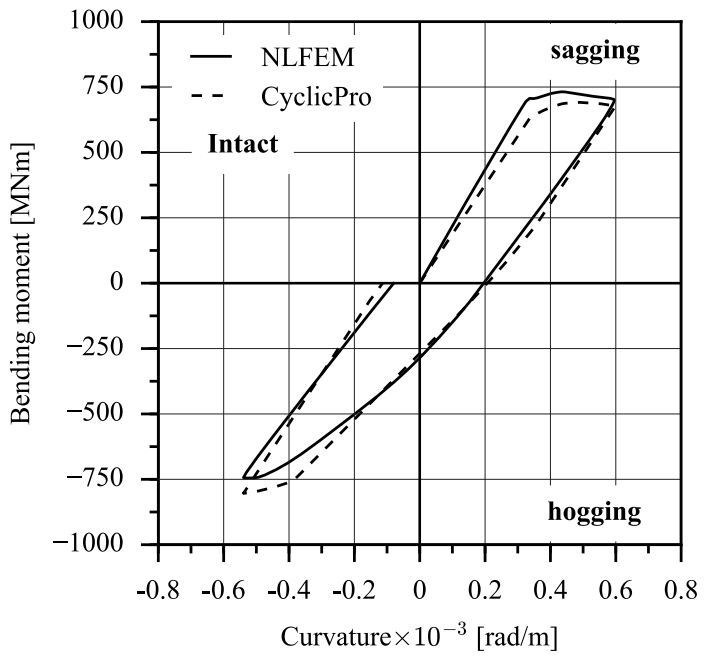

(a) Intact model

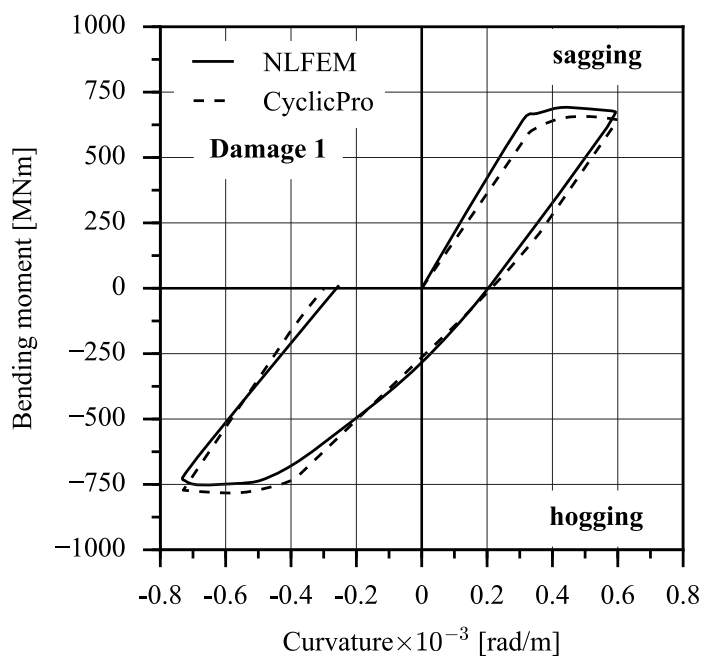

(b) Damaged model

Figure 8. Finite element validation (Cyclic analysis)

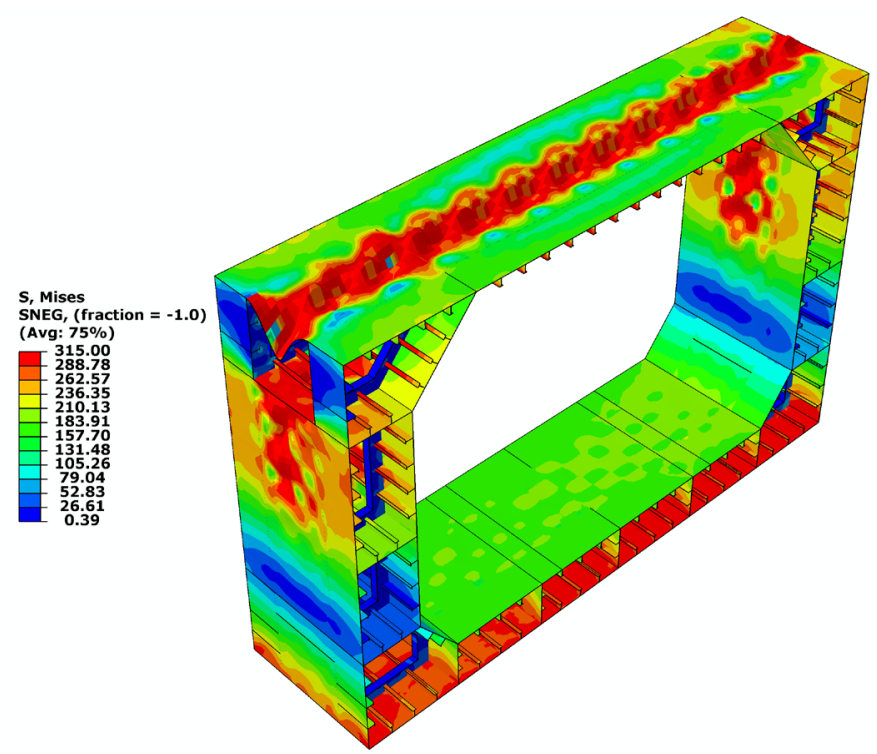

Figure 9. von-Mises stress contour plot of the damaged cross section at ultimate collapse state (sagging)

\subsection{The effect of cyclic loading}

The effect of cyclic loading on the reduction of bending strength is investigated. For each damage sce- 
nario, the cyclic progressive collapse analysis is performed under three different loading ranges in terms of the applied curvature, namely

- Case 1: $0.35 \times 10^{-3} \mathrm{rad} / \mathrm{m}$

- Case 2: $0.40 \times 10^{-3} \mathrm{rad} / \mathrm{m}$

- Case 3: $0.45 \times 10^{-3} \mathrm{rad} / \mathrm{m}$

As shown in Figure 10, the first loading range is representative as the initial failure in sagging and the third loading range is representative as the ultimate collapse state of sagging. The second one serves as an intermediate condition. The curvature is applied equally in sagging and hogging. Each loading range is applied from one cycle to five cycles.

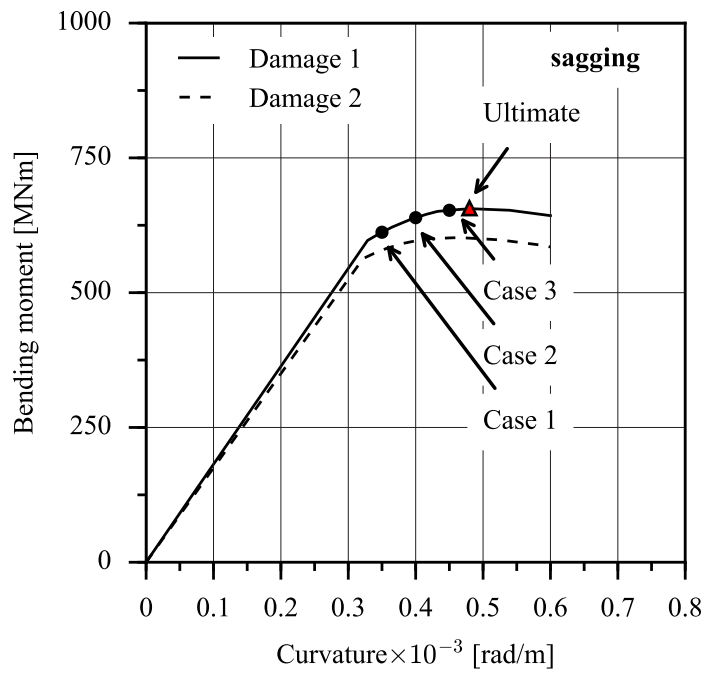

Figure 10. Three different loading ranges

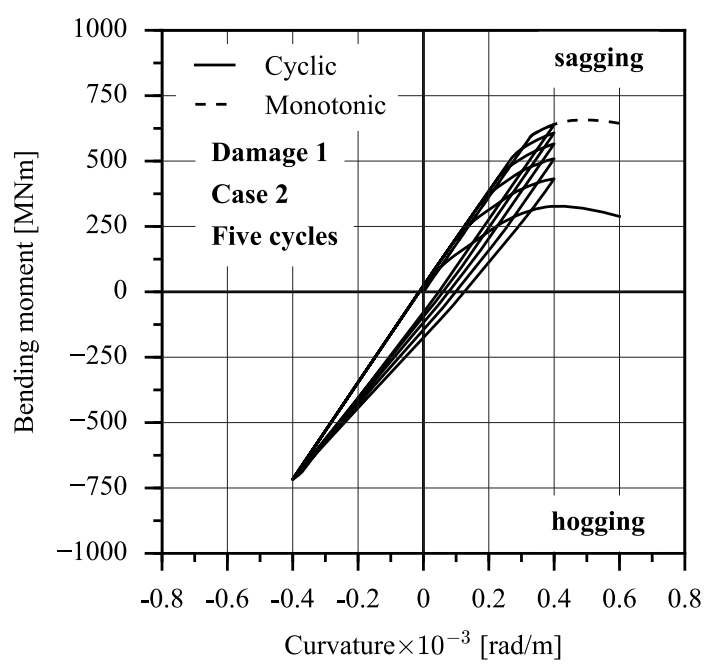

Figure 11. Cyclic bending moment-curvature relationship

A cyclic bending moment/curvature curve is given in Figure 11. The variations of the ultimate sagging strength during the cyclic loading are summarised in Figure 13 to 16 and Table 2 to 5 for four different damage scenarios. As a reference, the result of the intact cross section is given in Figure 12 and Table 2. It is evident that the reduction rate is significantly increased when the applied curvature range is larger.

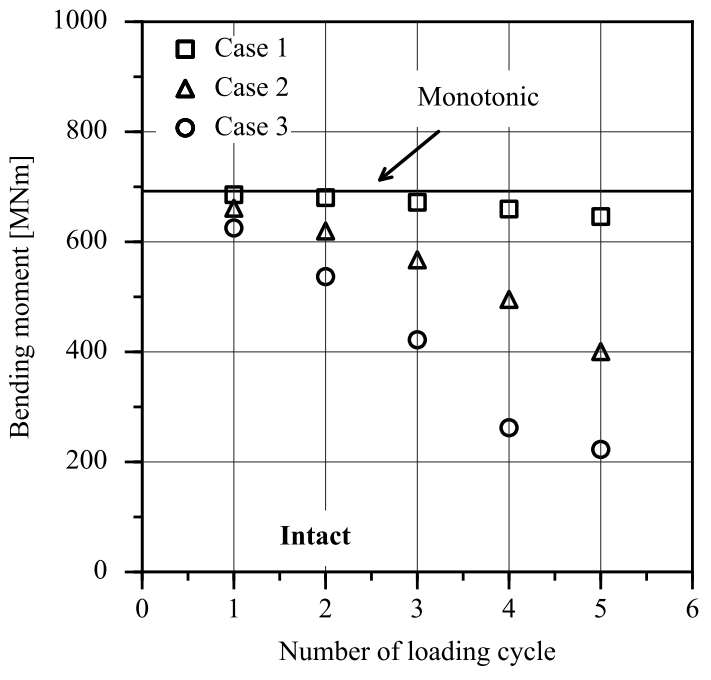

Figure 12. Variation of the ultimate sagging strength during cyclic loading (Intact)

Table 2. Reduction of the ultimate sagging strength during cyclic loading (Intact)

\begin{tabular}{cccccc}
\hline & $1^{\text {st }}$ & $2^{\text {nd }}$ & $3^{\text {rd }}$ & $4^{\text {th }}$ & $5^{\text {th }}$ \\
\hline Case 1 & $0.9 \%$ & $1.7 \%$ & $2.9 \%$ & $4.7 \%$ & $6.7 \%$ \\
Case 2 & $4.5 \%$ & $10.5 \%$ & $18.0 \%$ & $28.4 \%$ & $42.1 \%$ \\
Case 3 & $9.7 \%$ & $22.4 \%$ & $39.0 \%$ & $62.1 \%$ & $67.8 \%$ \\
\hline
\end{tabular}

For Case 1 loading, which is representative as the initial failure, the sagging strength reduction is $10 \%$ and $17.9 \%$ after five loading cycles when the cross section has a moderate and severe side shell damages respectively. On the contrary, the reduction is comparatively negligible when the cross section has a bottom damage.

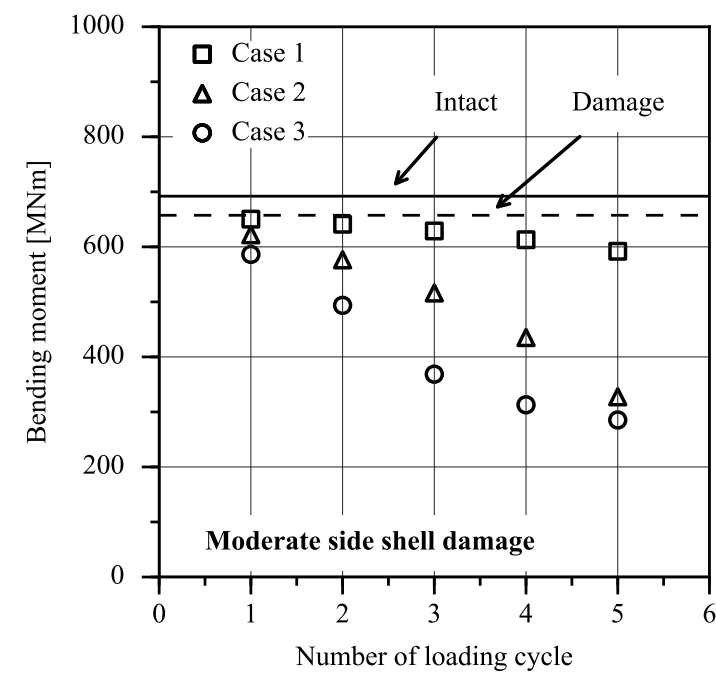

Figure 13. Variation of the ultimate sagging strength during cyclic loading (Moderate side shell damage)

Table 3. Reduction of the ultimate sagging strength during cyclic loading (Moderate side shell damage)

\begin{tabular}{cccccc}
\hline & $1^{\text {st }}$ & $2^{\text {nd }}$ & $3^{\text {rd }}$ & $4^{\text {th }}$ & $5^{\text {th }}$ \\
\hline Case 1 & $1.1 \%$ & $2.5 \%$ & $4.3 \%$ & $6.8 \%$ & $10.0 \%$ \\
Case 2 & $5.4 \%$ & $12.3 \%$ & $21.5 \%$ & $33.8 \%$ & $50.2 \%$ \\
Case 3 & $10.8 \%$ & $24.9 \%$ & $43.9 \%$ & $52.4 \%$ & $56.6 \%$ \\
\hline
\end{tabular}


For Case $2 \& 3$, a considerably large reduction is predicted after the first cycle. When the cross section is severely damaged on the side shell, there is $55 \%$ to $65 \%$ reduction after five loading cycles. However, it should be noted that the present LSC prediction methodology does not account for the compressive response convergence phenomenon, which means that the compressive strength is kept decreasing at each cycle. However the LSC tends to converge to a certain loop, as suggested by Li et al. (2019c) among others. It implies that, whist the bending strength can be appreciably reduced, the reduction might not be so conservative.

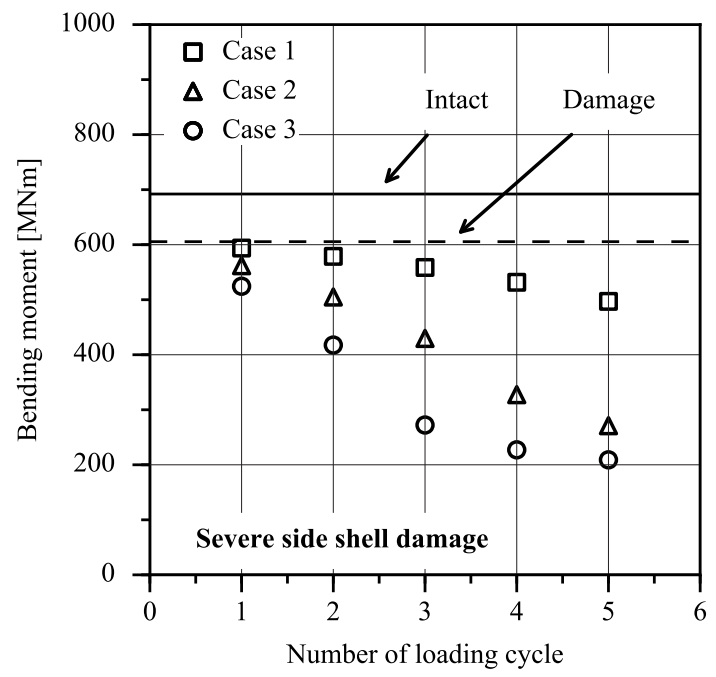

Figure 14. Variation of the ultimate sagging strength during cyclic loading (Severe side shell damage)

Table 4. Reduction of the ultimate sagging strength during cyclic loading (Severe side shell damage)

\begin{tabular}{cccccc}
\hline & $1^{\text {st }}$ & $2^{\text {nd }}$ & $3^{\text {rd }}$ & $4^{\text {th }}$ & $5^{\text {th }}$ \\
\hline Case 1 & $1.9 \%$ & $4.4 \%$ & $7.7 \%$ & $12.2 \%$ & $17.9 \%$ \\
Case 2 & $7.2 \%$ & $16.6 \%$ & $29.0 \%$ & $45.9 \%$ & $55.2 \%$ \\
Case 3 & $13.4 \%$ & $31.0 \%$ & $55.0 \%$ & $62.5 \%$ & $65.5 \%$ \\
\hline
\end{tabular}

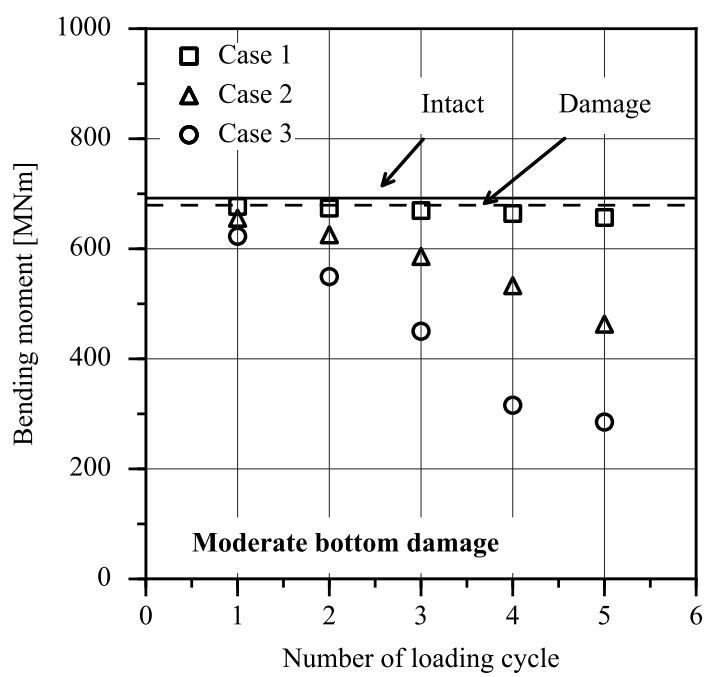

Figure 15. Variation of the ultimate sagging strength during cyclic loading (Moderate bottom damage)
Table 5. Reduction of the ultimate sagging strength during cyclic loading (Moderate bottom damage)

\begin{tabular}{lccccc}
\hline & $1^{\text {st }}$ & $2^{\text {nd }}$ & $3^{\text {rd }}$ & $4^{\text {th }}$ & $5^{\text {th }}$ \\
\hline Case 1 & $0.3 \%$ & $0.8 \%$ & $1.4 \%$ & $2.2 \%$ & $3.3 \%$ \\
Case 2 & $3.5 \%$ & $7.9 \%$ & $13.7 \%$ & $21.5 \%$ & $31.8 \%$ \\
Case 3 & $8.3 \%$ & $19.1 \%$ & $19.1 \%$ & $33.7 \%$ & $58.0 \%$ \\
\hline
\end{tabular}

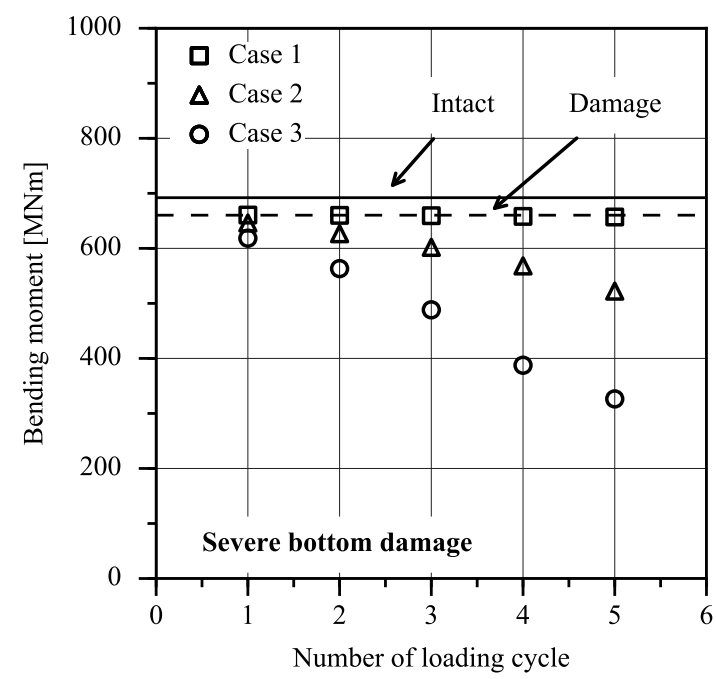

Figure 16. Variation of the ultimate sagging strength during cyclic loading (Severe bottom damage)

Table 6. Reduction of the ultimate sagging strength during cyclic loading (Severe bottom damage)

\begin{tabular}{cccccc}
\hline & $1^{\text {st }}$ & $2^{\text {nd }}$ & $3^{\text {rd }}$ & $4^{\text {th }}$ & $5^{\text {th }}$ \\
\hline Case 1 & $0.0 \%$ & $0.0 \%$ & $0.1 \%$ & $0.3 \%$ & $0.5 \%$ \\
Case 2 & $2.1 \%$ & $5.1 \%$ & $8.8 \%$ & $14.0 \%$ & $20.9 \%$ \\
Case 3 & $6.3 \%$ & $14.7 \%$ & $26.1 \%$ & $41.3 \%$ & $50.6 \%$ \\
\hline
\end{tabular}

\subsection{The effect of neutral axis rotation}

The effect of neutral axis rotation can be clarified by comparing the results between pure vertical bending and constrained vertical bending introduced in Section 3.2, in which the former accounts for the rotation and the latter does not.

Figure 17 compares the monotonic results of the severe side shell damage scenario where the effect of neutral axis rotation is included and excluded. It shows that the neutral axis rotation has an insignificant effect on the monotonic results. Meanwhile, the result excluding the effect of rotation is slightly higher than that including the effect of rotation. This is in agreement with the investigation by Fujikubo et al. (2012), in which it is suggested that the neutral axis rotation has a small effect on the residual ultimate strength when only the outer shell is damaged.

Figure 18 illustrates the effect of neutral axis rotation on the ultimate sagging strength during cyclic loading. Generally, the rotation of neutral axis also has a small effect on the cyclic analysis. However, the difference seems to become relatively significant after five loading cycles. 


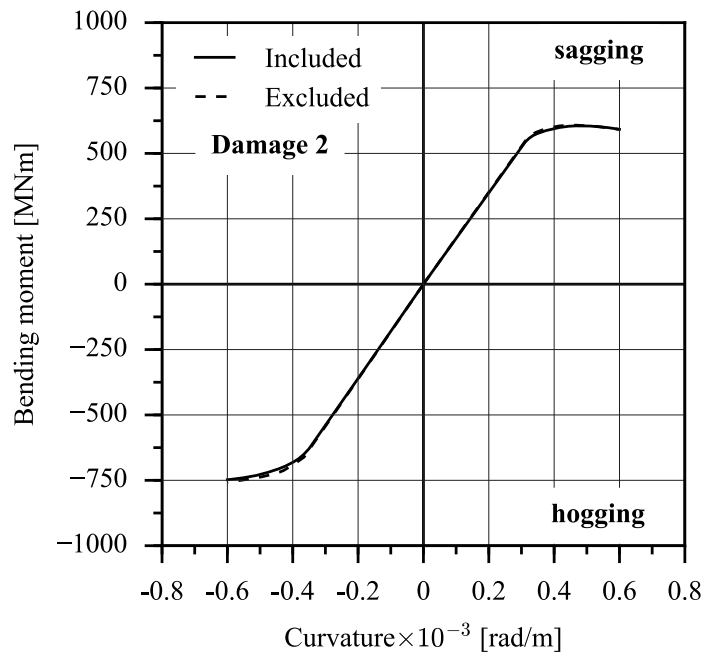

Figure 17. The effect of neutral axis rotation on the monotonic bending moment-curvature relationship

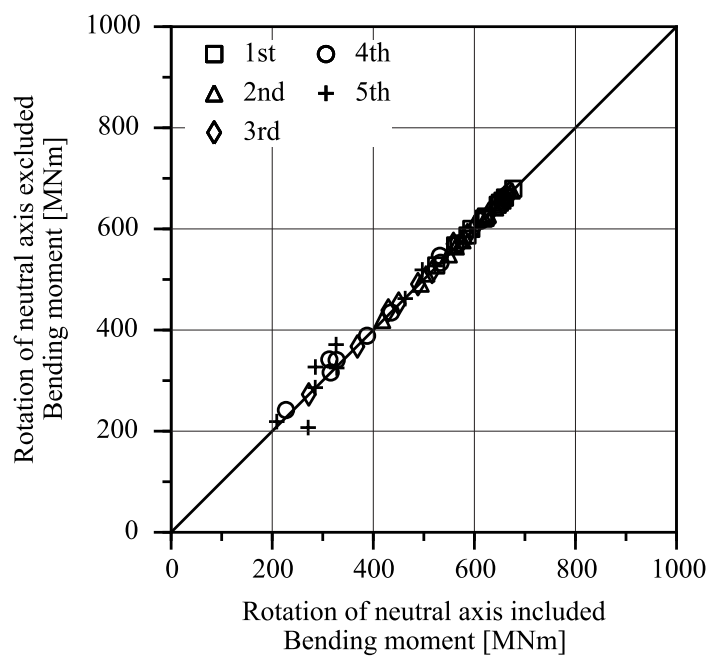

Figure 18. The effect of neutral axis rotation on the ultimate sagging strength during cyclic loading

\section{RECOMMENDATION}

The case study has analysed the variation of ultimate bending strength of a hull girder due to the cyclic loading, in which a large reduction is predicted. However, the reduction might be overestimated, as the convergence of compressive response is not considered in the LSC prediction of present study. To take this into account, Li et al. (2019c) introduced a postultimate stiffness reduction factor in the analytical method for cyclic LSC. With this being properly defined, a more reasonable bending strength reduction during cyclic loading can be estimated.

It is shown in this paper that the neutral axis rotation only has a small influence on the cyclic analysis. It is worthwhile to investigate whether it still holds for a cross section with a larger damage extent where the damage zone expands into the inner hull.

\section{CONCLUSION}

This paper applies the cyclic progressive collapse method to investigate the bending response and sagging strength variation of an asymmetrically damaged ship hull girder under cyclic loading. Equivalent finite element analysis is performed as a validation. The following conclusions can be drawn:

- The cyclic progressive collapse method can be applied to predict the bending response of a damaged ship hull girder;

- During the cyclic loading, there is a considerably large bending strength reduction of the hull girder

- The reduction rate is associated with the applied curvature range;

- The neutral axis rotation only has a small effect on the result of cyclic analysis;

\section{REFERENCE}

$14^{\text {th }}$ ISSC, 2000. Ultimate Strength. ISSC Committee III.1. Nagasaki, Japan.

$15^{\text {th }}$ ISSC, 2003. Ultimate Strength. ISSC Committee III.1. San Diego, United States.

$20^{\text {th }}$ ISSC, 2018. Ultimate Strength. ISSC Committee III.1. Delft, Netherlands.

Cui, H., Yang, P., 2018. Ultimate strength and failure characteristics research on steel box girders under cyclic-bending moments. Journal of Marine Science and Technology.

Dow, R.S., Hugill, R.C., Clark, J.D., Smith, C.S., 1981. Evaluation of ultimate ship hull strength. In: SSC-SNAME Extreme Loads Response Symposium, Arlington, VA, USA.

Fujikubo, M., Zubair Muis Alie, M., Takemura, K., Iijima, K., Oka, S., 2012. Residual hull girder strength of asymmetrically damaged ships. Journal of the Japan Society of Naval Architects and Ocean Engineers 16, 131-140.

Guedes Soares, C., Luís, R., M., Nikolov, P., Downes, J., Taczala, M., Modiga, M., Quesnel, T., Toderan, C., Samuelides, M., 2008. Benchmark study on the use of simplified structural codes to predict the ultimate strength of a damaged ship hull. International Shipbuilding Progress 87-107.

Hess, P.E., Adamchak, J.C., Falls, J., 1997. Failure analysis of an inland waterway oil bunker tanker. Survivability, structures, and material directorate technical report. Naval surface warfare center, Carderock division.

Li, S., Hu, Z.Q., Benson, S.D., 2019a. A cyclic progressive collapse method to predict the bending response of a ship hull girder. In: $7^{\text {th }}$ International Conference on Marine Structures (MARSTRUCT), Dubrovnik, Croatia.

Li, S., Benson, S.D., 2019b. A re-evaluation of the hull girder shakedown limit states. Ships and Offshore Structures.

Li, S., Hu, Z.Q., Benson, S.D., 2019c. Load-shortening characteristics and prediction of plate and stiffened panel under cyclic compression and tension. Engineering Structures (Under review).

Masaoka, K., Nagao, M., Shibahara, M., Tsubogo, T., 2006. Experimental study on collapse behavior of a stiffened box-section girder under cyclic loading. In: Symposium on welded structure.

Paik, J.K., Thayamballi, A.K., 1997. In Proceedings: An empirical formulation for predicting the ultimate compressive strength of stiffened panels. In: International Conference on Offshore and Polar Engineering, 328-338 Honolulu, Hawaii

Smith, C.S., 1977. Influence of local compressive failure on ultimate longitudinal strength of a ship's hull. In: International Symposium on Practical Design of Ships and others Floating Structures (PRADS), Tokyo, Japan. 